\title{
Effects of short-term warm water immersion on cardiac baroreflex sensitivity in healthy men
}

\author{
Jun Sugawara ${ }^{1 *}$ (D) and Tsubasa Tomoto 2,3
}

\begin{abstract}
Warm water immersion (WWI) causes dizziness presumably due to a substantial drop of blood pressure. The aim of this study was to elucidate the effects of short-term WWI on cardiac baroreflex sensitivity (BRS) and the contribution of arterial stiffness to the cardiac BRS. Twelve apparent healthy men ( $44 \pm 12$ years) performed the single stand-up test after 5 -min sitting in the bathtub without (Control) and with $41{ }^{\circ} \mathrm{C}$ warm water at the heart level (WWI). Cardiac BRS gain was evaluated by R-R interval response to the standing-induced drop of systolic blood pressure. In addition, before and 10 min after the single stand-up test, carotid arterial $\beta$-stiffness index was evaluated in the supine rest. BRS gain was blunted (2.9 \pm 1.6 vs. $1.8 \pm 1.1 \mathrm{~ms} / \mathrm{mmHg}, P=0.005)$, whereas $\beta$-stiffness index was not changed significantly after WWI. BRS gain correlated with $\beta$-stiffness index before $(r=-0.626, P=0.028)$ and after WWI $(r=-0.672$, $P=0.015)$. ANCOVA revealed that these slopes of linear regression lines remained unchanged after $W W I(P=0.350)$. These results indicate that a short-term WWI acutely deteriorates cardiac BRS. Individuals with stiffer arteries are relatively more susceptible to WWI because of their poor baseline BRS, which might be one of the causes of bathingrelated falling in elderly persons as well as frailty.
\end{abstract}

Keywords: Warm water immersion, Blood pressure, Cardiac baroreflex, Arterial stiffness

\section{Background}

Passive heat therapy seems to be capable of inducing improvements in vascular health $[4,17]$. Thus, it could be a promising approach which has potential to reduce cardiovascular disease risk, incidence of cardiovascularrelated mortality, sudden cardiac death, and all-cause mortality [12]. However, bath-related fatal (e.g., sudden cardiac arrest) and non-fatal accidents (e.g., dizziness and disturbance of consciousness) have been reported frequently in Japan that has a traditional custom to daily warm water immersion (WWI) in the bathtub at the bathing. Regarding non-fatal accidents, it is wellknown empirically that immediately after WWI feeling dizzy on standing up frequently occurs presumably

\footnotetext{
${ }^{*}$ Correspondence: jun.sugawara@aist.go.jp

${ }^{1}$ Human Informatics and Interaction Research Institute, National Institute of Advanced Industrial Science and Technology, 1-1-1 Higashi, Tsukuba, Ibaraki 305-8566, Japan

Full list of author information is available at the end of the article
}

due to a substantial drop of blood pressure which could be a risk for fall-down and syncope. Yet, the underlying mechanism of bathing-related accidents remains to be determined.

Orthostatic challenge results in transient reductions of cardiac output and mean arterial pressure (MAP), and hence concomitant decreases in cerebral perfusion pressure and blood flow because blood is displaced from the thorax to the lower body [20]. In this situation, maintaining adequate blood pressure via baroreflex is likely to be an important regulatory mechanism in tolerating orthostatic hypotension and avoiding syncope [20]. Importantly, standing-induced reductions in cerebral perfusion tend to be exacerbated in the heat due to the large redistribution of central blood volume to the cutaneous vascular bed for thermoregulation [5]. Thus, several studies have been performed to investigate the effect of passive heat stress on baroreflex control of blood pressure and inconsistent results about impact on cardiac baroreflex sensitivity (BRS) are reported. The maximal gain between 
arterial pressure and heart rate (HR) was not changed significantly after whole body heating via water-perfused suits $[7,27,28]$, and blunted cardiac BRS gain could be confirmed by use of the relationship between arterial pressure and R-R interval (RRI) [7]. Transfer function analysis reveals that passive heat stress reduces dynamic regulation of cardiac BRS gain [8]. In addition, heat stress blunts the response time of carotid-cardiac and carotidvasomotor baroreflexes [29]. Thus, prolonged heat stress and hypohydration seem to impair orthostatic tolerance [5]. However, the impact of short-term WWI which might not to induce hypohydration on cardiac BRS has never been clarified.

A more important issue is that previous results may not provide us adequate answer to aforementioned question of underlying mechanism of non-fatal accidents immediately after WWI because of no-real world experimental setting (e.g., water-perfused suits and carotid baroreceptor-selective stimulation via neck chamber) [7, 8, 27-29]. In the case of bathing, getting out the bathtub is associated with integrated stimulations of (1) the combined unloading of aortic and carotid arterial baroreceptors and (2) absence of hydraulic compression to dilated vessels in the lower extremities. Therefore, we evaluated cardiac BRS at the action of getting out from the bathtub, the practical situation, in the present study.

Generally, blood pressure is well-regulated instantly by sensing fluctuation of blood pressure via baroreceptors located at the aortic arch and carotid arteries [18, 19]. Since these are mechanoreceptors, arterial stiffness is associated with sensitivity of baroreceptors [18]. Indeed, a large cohort study revealed that the increased arterial stiffness could be attributed to impaired cardiac baroreflex sensitivity [15] and exacerbated postural hypotension [16]. However, influence of WWI on the relationship between arterial stiffness and BRS remains unclear.

The aims of this study were to elucidate the effects of short-term WWI on cardiac BRS in healthy men, and the contribution of arterial stiffness to the change in cardiac BRS with WWI. The hypotheses of this study were that a short-term warm water bathing deteriorates cardiac BRS, and that individual changes in arterial stiffness with WWI are attributed to the response of cardiac BRS to WWI

\section{Methods}

\section{Subjects}

To determine the contribution of arterial stiffness to the change in cardiac BRS with WWI, we set inclusion criteria were men aged between 20 and 60 years who were not medicated individuals, having overt cardiovascular diseases as assessed by medical history, and current smokers. Twelve healthy men (27-57 y.o., mean age of $44 \pm 11$ y.o., height of $171.0 \pm 4.6 \mathrm{~cm}$, weight of $67.0 \pm 10.8 \mathrm{~kg}$, body mass index of $23.0 \pm 3.9 \mathrm{~kg} / \mathrm{m}^{2}$, body fat of $17.3 \pm 7.8 \%$, mean $\pm \mathrm{SD}$ ) were studied.

\section{Experimental protocol}

Subjects were instructed to abstain from alcohol intake and strenuous physical activity for at least $24 \mathrm{~h}$ prior to study. Furthermore, all measurements were performed after $3 \mathrm{~h}$ of fasting and an abstinence from caffeine. Upon arrival, subjects underwent height and body mass assessments. The following procedure (Fig. 1) was performed by wearing only swim shorts (no shirt). Each subject was instrumented for finger arterial pressure waveform measurement (via Finometer system) and received more than 5 min of quiet resting in the sitting posture on the floor of bathtub (no water) with arterial pressure recording. When blood pressure and HR (e.g., pulse rate) reached steady, each subject underwent the single stand-up test which consists 5-min sitting on the floor of the bathtub and 1-min standing in the bathtub. Each subject was instructed to keep quietly during sitting and standing. To confirm reproducibility of BRS evaluation, each subject repeated the single stand-up test twice (e.g., the first and second test) in the bathtub without water (control condition) with the 5-min interval. After the completion of 2 single stand-up tests, each subject was removed Finometer system and moved to the bed in a quiet, temperaturecontrolled room $\left(24-26^{\circ} \mathrm{C}\right)$. Each subject took 10-min supine rest which followed by the first vascular measurement. After the vascular measurement, subject returned to the bathroom and performed the third single standup test with re-instrumented Finometer system ( $5 \mathrm{~min}$ of sitting on the floor of bathtub with $41^{\circ} \mathrm{C}$ warm water at the heart level, which was followed by $1 \mathrm{~min}$ of quiet standing in the bathtub: WWI condition). After this test, each subject wiped out his body quickly and took 10-min quiet supine rest, which was followed by the second vascular measurement.

\section{Measurements \\ Vascular measurements}

HR and brachial blood pressure (BP) were measured with the cardiovascular screening device (VP-1000 plus; Omron Healthcare, Kyoto, Japan). Carotid arterial $\beta$-stiffness index, an index of arterial stiffness adjusted for distending pressure, was also measured as we previously reported [24]. In brief, the B-mode longitudinal ultrasound images of the left common carotid were recorded using an ultrasound device with a high-resolution (14 MHz) linear transducer (CX50xMATRIX; Philips Ultrasound, Bothell, WA) and were analyzed offline using automatic edge-detection software (Vascular Tool 5; Medical Imaging Applications, Coralville, IA). 


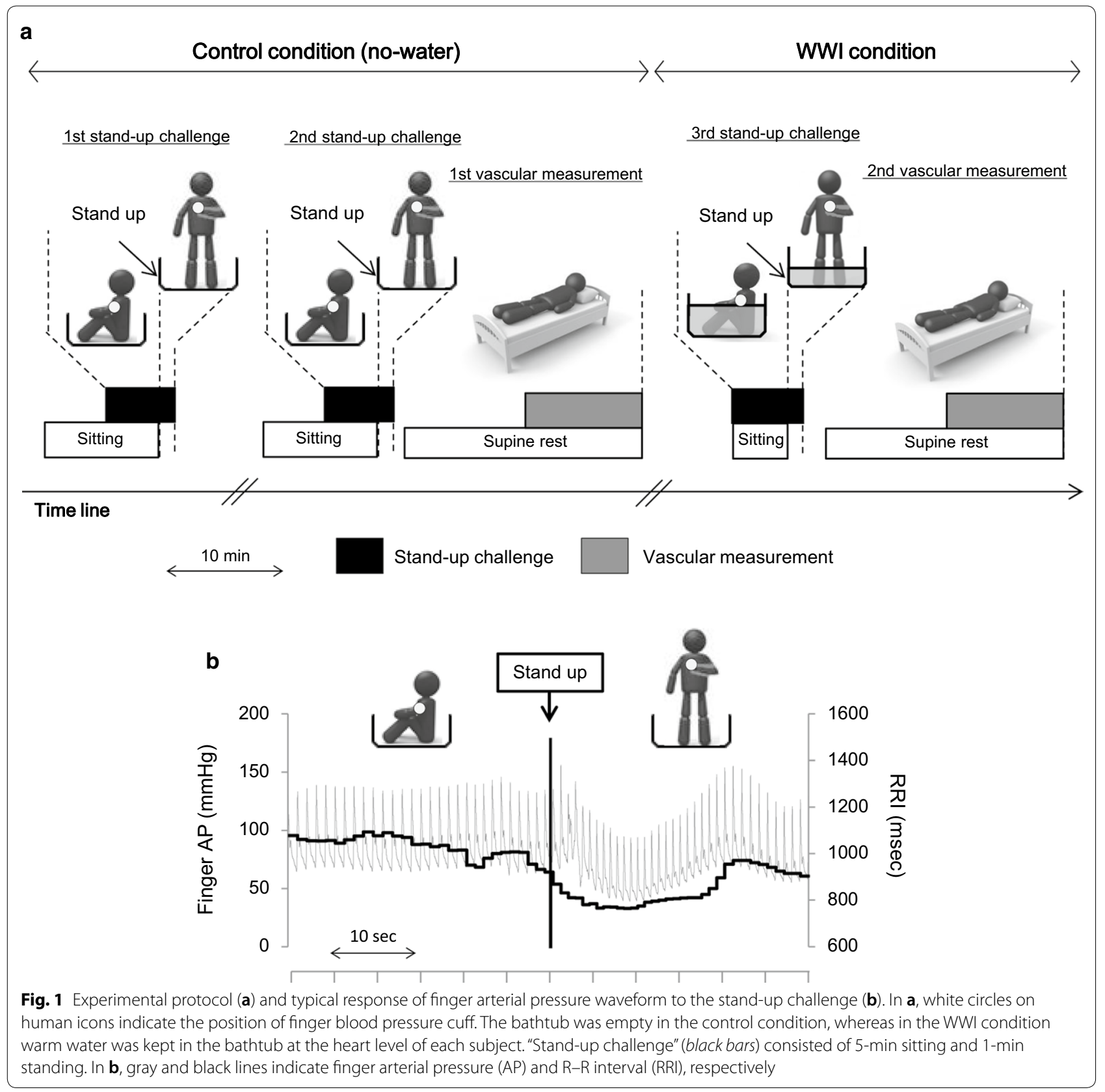

Carotid arterial pressure waveforms were obtained with arterial applanation tonometry incorporating an array of 15 micropiezoresistive transducers (VP-2000, Colin Medical, Komaki, Japan), and were calibrated by equating the carotid mean arterial and diastolic BP to the brachial mean arterial and diastolic BP [2]. Those were calibrated by equating the carotid mean arterial and diastolic BP to the brachial artery values. $\beta$-Stiffness index, an index of arterial compliance adjusted for distending pressure, was calculated using the following equation: $\ln \left(P_{1} / P_{0}\right) /$ $\left[\left(D_{1}-D_{0}\right) / D_{0}\right]$, where $D_{1}$ and $D_{0}$ are the maximal and minimum diameters, and $P_{1}$ and $P_{0}$ are carotid arterial pressure at peak systole and end diastole.

\section{Cardiac baroreflex sensitivity}

Arterial pressure waveform was continuously recorded at the left middle finger by Finometer system (Finometer MIDI, Finapres Medical Systems, Amsterdam, The Netherlands) during the single stand-up test, and stored on a computer using a data acquisition system (PowerLab, AD Instrument) at the $1000 \mathrm{~Hz}$ of sampling rate. Throughout the test, subject was asked to keep the left hand at 
the heart level: on the side-table out of the bathtub during sitting and on the chest during standing. These data were analyzed offline by flexible data analysis software (LabChart, ADInstrument). Cardiac BRS gain was evaluated by the sequence method (e.g., the slope of linear regression line between standing-induced abrupt drop of systolic blood pressure (SBP) and corresponding reduction in RRI). RRI was estimated from the time interval between the systolic foot and the next systolic foot of arterial pressure waveforms. The slope of linear regression line was calculated from the continuous reduction of SBP and corresponding change in RRI (without time-lag) as long as possible (at least more than 3 beats). A correlation coefficient $(r)>|0.85|$ was included in the analysis [28]. Hemodynamic variables during the single stand-up test were evaluated using a beat-to-beat hemodynamics analyzing software incorporated the validated stroke volume (SV) estimation (via Modelflow method $[22,25]$ ). Finger systolic and diastolic BP, MAP, HR, SV, cardiac output $(\mathrm{CO}=\mathrm{HR} \times \mathrm{SV})$, and systemic vascular resistance $(\mathrm{SVR}=\mathrm{MAP} / \mathrm{CO})$ were measured beat-to-beat manner throughout the single stand-up test (e.g., 5-min sitting, the stand-up motion, and 1-min standing). To determine the impact of WWI, averaged systemic hemodynamic variables were calculated from 3.5 to $4.5 \mathrm{~min}$ of sitting.

\section{Body temperature}

Tympanic membrane temperature was measured $30 \mathrm{~s}$ before the standing in both conditions by the infrared tympanic thermometer (Genius 2, GOVIDIEN, Mansfield, MA, USA).

\section{Statistical analyses}

To evaluate reproducibility of BRS measurement, intraclass correlation coefficient (ICC) and 95\% limits of agreement were calculated from two measurements of BRS gain at the control condition. Paired $t$ test was applied for comparison between two conditions. Simple correlation analysis was performed to determine relations of interests. The slopes of linear regression line between $\beta$-stiffness index and BRS gain were compared by interaction between time and $\beta$-stiffness index on BRS gain by ANCOVA. All data are reported as mean \pm SD. Statistical significance was set a priori at $P$ values less than 0.05 .

\section{Results}

Table 1 summarizes systemic hemodynamics and tympanic temperature during sitting in the bathtub. HR and $\mathrm{CO}$ were significantly increased during WWI, whereas
Table 1 Tympanic temperature and systemic hemodynamics during sitting in the bathtub without (control) and with warm water (WWI)

\begin{tabular}{lccl}
\hline Variables & Control & WWI & $P$-value \\
\hline Tympanic temperature, ${ }^{\circ} \mathrm{C}$ & $36.4 \pm 0.3$ & $36.4 \pm 0.3$ & 0.999 \\
Heart rate, beats/min & $62 \pm 8$ & $68 \pm 8$ & 0.017 \\
Finger systolic BP, mmHg & $107 \pm 17$ & $107 \pm 17$ & 0.961 \\
Finger diastolic BP, mmHg & $58 \pm 14$ & $62 \pm 14$ & 0.210 \\
Finger MAP, $\mathrm{mmHg}$ & $74 \pm 15$ & $77 \pm 14$ & 0.278 \\
Stroke volume, $\mathrm{mL}$ & $84.6 \pm 17.2$ & $83.5 \pm 16.2$ & 0.760 \\
Cardiac output, L/min & $5.2 \pm 0.9$ & $5.6 \pm 1.2$ & 0.022 \\
Systemic VR, $\mathrm{mmHg}$ min/L & $15.2 \pm 6.3$ & $14.6 \pm 6.0$ & 0.556 \\
\hline
\end{tabular}

Data are mean and SD. Systemic hemodynamic variables were averaged values from 3.5 to $4.5 \mathrm{~min}$ of the sitting period

$B P$ blood pressure, $M A P$ mean arterial pressure, $V R$ vascular resistance
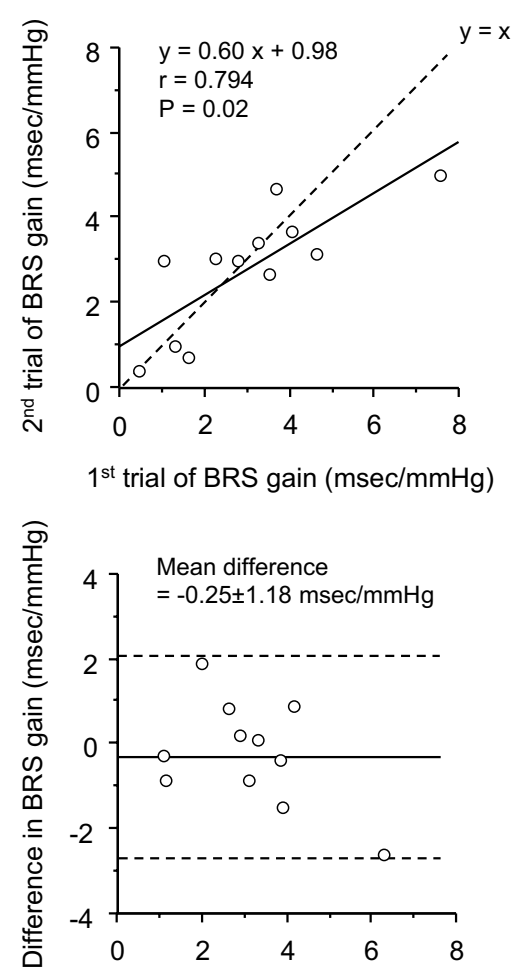

Average of BRS gain ( $\mathrm{msec} / \mathrm{mmHg}$ )

Fig. 2 Reproducibility of cardiac baroreflex sensitivity (BRS) gain evaluated by the single stand-up test: scatter plot (a) and Brand and Altman's plot (b)

MAP, SV, SVR, and tympanic temperature did not change significantly.

Regarding reproducibility of BRS gain by the single stand-up challenge, ICC was $0.749(P=0.002$, Fig. 2). Mean difference and $95 \%$ limits of agreement 
were $-0.25 \pm 1.18$ and from -2.55 to $2.06 \mathrm{~ms} / \mathrm{mmHg}$, respectively. Thus, the averaged value of two bouts was calculated as BRS gain in the control condition.

Figure 1 depicts typical response of MAP and RRI to a stand-up motion. There were no significant differences in either the baseline (sitting) finger artery MAP (from $73 \pm 16$ to $77 \pm 16 \mathrm{mmHg}, P=0.322$ ) or the standinginduced decreases in finger artery MAP (from $-33 \pm 12$ to $-33 \pm 13 \mathrm{mmHg}, P=0.970$ ) between two conditions (Table 2). The number of beats used for SBP-RRI slope calculation was significantly smaller in the WWI than the control condition $(P=0.007)$, where linear regression coefficients were equivalent between two conditions $(P=0.719)$. BRS gain was significantly blunted after the bathing (from $3.04 \pm 1.93$ to $1.78 \pm 1.15 \mathrm{~ms} / \mathrm{mmHg}$, $P=0.014$, Fig. 3).

Regarding vascular measurements, HR (from $56 \pm 6$ to $54 \pm 6$ beat $/ \mathrm{min}, P=0.025$ ) and brachial diastolic BP (from $72 \pm 12$ to $69 \pm 8 \mathrm{mmHg}, P=0.030$ ) were significantly decreased in the 2nd measurement (e.g., $10 \mathrm{~min}$ after the end of WWI) than those in the 1st measurement (e.g., before WWI), whereas brachial systolic BP (from $114 \pm 14$ to $110 \pm 11 \mathrm{mmHg}, P=0.126)$ and $\beta$-stiffness index (from $5.3 \pm 1.5$ to $5.1 \pm 1.1, P=0.603$, Fig. 3 ) did not change significantly.

As shown in Fig. 4, BRS gain correlated with $\beta$-stiffness index both the control $(r=-0.626, P=0.028)$ and WWI $(r=-0.672, P=0.015)$ conditions. ANCOVA revealed that the slopes of linear regression line between $\beta$-stiffness index and BRS gain remained unchanged after WWI (interaction: $P=0.350$ ).

\section{Discussion}

Main results of this study are as follows: first, cardiac BRS gain was blunted after the 5 -min WWI. Second, BRS gain correlated with carotid arterial $\beta$-stiffness index before

Table 2 Hemodynamic response to the stand-up challenge without (control) and with warm water (WWI)

\begin{tabular}{lccl}
\hline Variables & Control & WWI & P-value \\
\hline Baseline HR, beat/min & $62 \pm 7$ & $72 \pm 9$ & 0.003 \\
Baseline MAP, mmHg & $73 \pm 16$ & $77 \pm 16$ & 0.322 \\
Nadir MAP, mmHg & $43 \pm 8$ & $46 \pm 12$ & 0.364 \\
Delta MAP, mmHg & $-33 \pm 11$ & $-34 \pm 14$ & 0.700 \\
Beat to nadir MAP, beats & $13 \pm 2$ & $11 \pm 4$ & 0.235 \\
Number of data plots, $n$ & $6.3 \pm 1.5$ & $4.8 \pm 1.3$ & 0.007 \\
Correlation coefficient & $0.964 \pm 0.022$ & $0.968 \pm 0.027$ & 0.719 \\
\hline
\end{tabular}

Data are mean and SD. Baseline data were averaged values for $10 \mathrm{~s}$ immediately before the stand-up motion. $H R$ heart rate, MAP finger artery mean arterial pressure. Number of data plot and correlation coefficient were obtained from the regression line calculation data between finger systolic blood pressure and $\mathrm{R}-\mathrm{R}$ interval

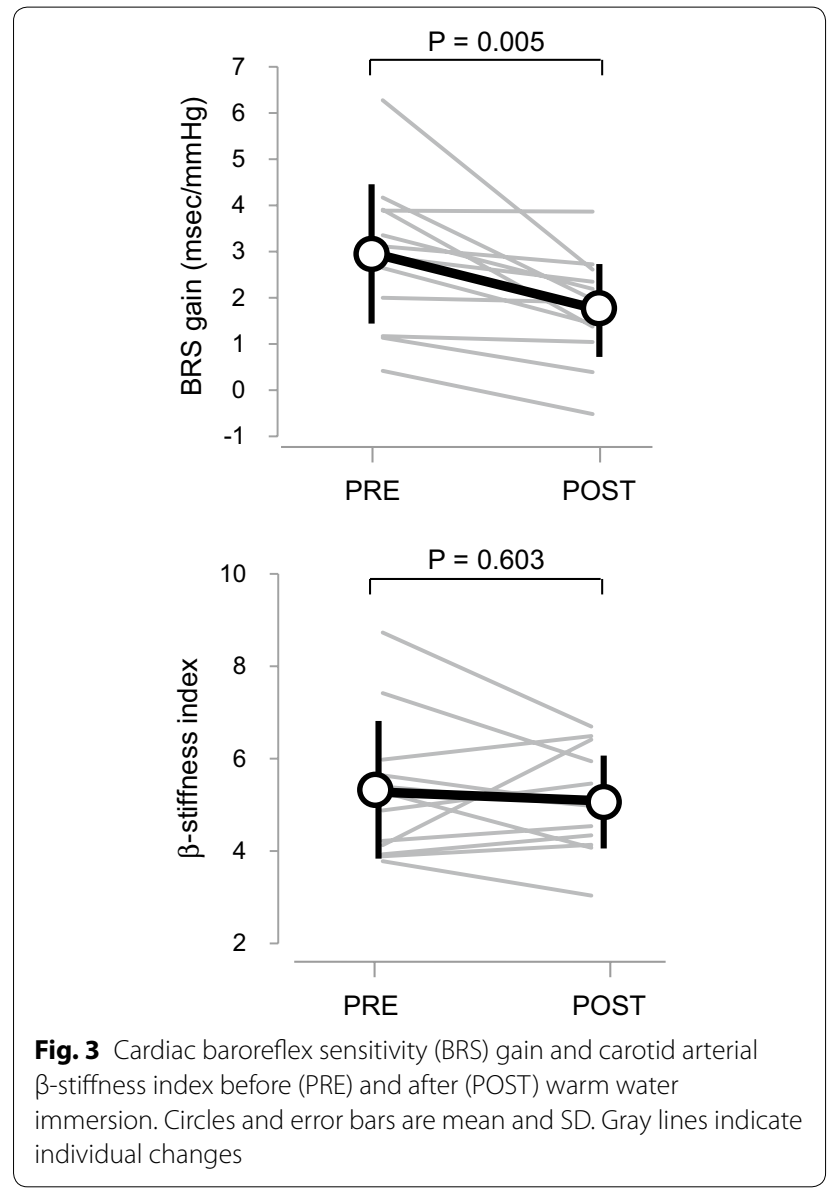

$(r=-0.626, P=0.028)$ and after WWI $(r=-0.672$, $P=0.015)$, and the slopes of linear regression line between $\beta$-stiffness index and BRS gain remained similar after WWI. These results indicate that a short-term WWI acutely deteriorates cardiac BRS. Individuals with stiffer arteries are relatively more susceptible to WWI because of their poor baseline BRS, which might be one

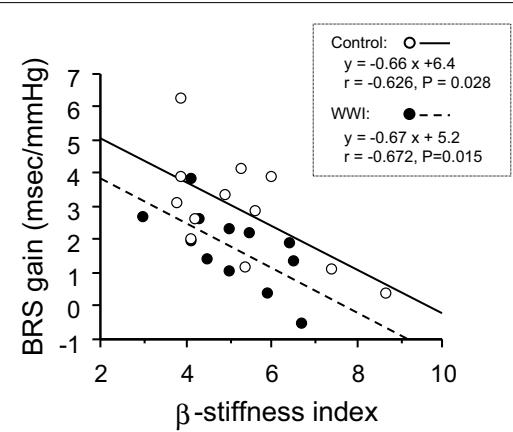

Fig. 4 Relationships between carotid arterial $\beta$-stiffness index and cardiac baroreflex sensitivity (BRS) gain before (control) and after warm water immersion (WWI) 
of the causes of bathing-related falling in elderly persons as well as frailty.

Bath-related accidents (e.g., dizziness and disturbance of consciousness) have been reported frequently in Japan that has a traditional custom to daily warm water immersion (WWI) in the bathtub at the bathing. It is well-known empirically that immediately after WWI feeling dizzy on standing up frequently occurs presumably due to a substantial drop of blood pressure. Because of hydraulic pressure, impacts of aortic, carotid, and cardiopulmonary baroreceptor unloading might be different between supine and standing postures, and thus, response of cardiac BRS to orthostatic challenge with heat stressor would depend on postural setting. Thus, we evaluated cardiac BRS by use of the more practical setting (e.g., stand-up motion after WWI in the bathtub).

The maintenance of BP by baroreflex is critical for preserving cerebral perfusion and orthostatic intolerance. Thus, several studies have been performed to investigate the effect of prolonged passive heat stress accompanied by core temperature elevation on baroreflex control of BP. For instance, whole body heating via water-perfused suits did not alter carotid-cardiac baroreflex function evaluated by the maximal gain between arterial pressure and HR [7, 27, 28], whereas it is decreased when it is evaluated by the relationship between arterial pressure and $\mathrm{R}-\mathrm{R}$ interval (RRI) [7]. Transfer function analysis reveals that passive heat stress reduces dynamic regulation of cardiac BRS gain [8]. Inconsistent results of baroreflex control of HR might be due to the difference method to evaluate BRS [7, 8]. At least, BRS evaluated using RRI seems to be more sensitive than that based on HR, especially when HR is increased [7]. Given that vagal and sympathetic activity directly influence the slope of pacemaker potential, evaluation using RRI appears to be more reasonable to analyze the stress-associated autonomic response. Accordingly, in the present study, we evaluated cardiac BRS by the relationship between systolic BP and RRI responses.

Prolonged heat exposure with core temperature elevation and hypohydration decreases cardiac baroreflex control of HR [7, 8]. Importantly, the present study indicated that a short-term warm water bathing (e.g., $5 \mathrm{~min}$ ) without core temperature change deteriorates cardiac BRS. Our results seem to be practically important despite the similarity to previous studies and might extend our physiological understanding of BRS.

High arterial stiffness is associated with lower BRS [18] since the aortic and carotid baroreceptors are stretch receptors. Consistent to the previous study [18], we found that cardiac BRS was significantly and inversely correlated with carotid arterial $\beta$-stiffness index before the WWI. Interestingly, after the WWI carotid arterial $\beta$-stiffness index remained unchanged, whereas cardiac BRS was significantly blunted. Furthermore, correlation between BRS gain and $\beta$-stiffness index was still significant after the WWI with remaining the slopes of linear regression line. Collectively, we might speculate that heat stress did not affect peripheral arc but neural pathway of baroreflex. In any case, individuals with high arterial stiffness (i.e., older populations) may have higher risk for orthostatic intolerance and syncope after the bathing.

In this study, MAP reduced approximately $30 \mathrm{mmHg}$ at the single sit-stand motion from the floor of the bathtub irrespective of conditions. Such instant hypotensive responses were relatively greater than previous studies which used other techniques (i.e., neck chamber, lower body negative pressure, thigh cuff release) $[7,8,14$, 28]. We would like to emphasize that cardiac BRS was blunted by WWI under the present experimental setting; however, no subjects exhibited symptom of pre-syncope on this study. Generally, autoregulation, cardiac BRS, and arterial BRS regulate cerebral perfusion and systemic blood pressure to steady-state against the short-term (i.e., seconds to minutes) $[10,30]$. Thus, the other mechanisms including arterial and cardiopulmonary BRS [11] might compensate the deteriorated cardiac BRS.

\section{Experimental considerations}

First, because of the experimental setting (e.g., water immersion in the bathtub), we could not determine sensitivity of aortic, carotid, cardiopulmonary baroreceptors, separately. However, it looks more practical and real-world setting. Second, only men participated in this study. It remains unclear whether WWI similarly affects cardiac BRS in women. Women have lower orthostatic tolerance than men $[6,9,26]$, and more commonly faint when exposed to quiescent standing in warm environments [1]. Further studies are warranted among women for generalizability. Third, we posed the potential contribution of hydraulic pressure on the lower body to hemodynamics during hot bathing. However, we failed to answer the question posed because we did not analyze stand-up stress under the presence or absence of hydraulic pressure. Comparison of hemodynamic change among an intact stand-up challenge, after $30^{\circ} \mathrm{C}$ (nearly skin temperature) and $42{ }^{\circ} \mathrm{C}$ water immersion may allow answering this question.

Heat therapy using hot baths and saunas has been utilized with reports of improved quality of life and overall improved well-being in patients with type II diabetes mellitus [3]. It seems to be a promising intervention to reduce incidence of cardiovascular disease-related mortality, sudden cardiac death and all-cause mortality [12]. On the other hand, a recent prospective survey of the emergency events related to bathing reveals that 
consciousness disturbance and exhaustion are most frequent symptoms and which are presumably attributed to hyperthermia and dehydration [23]. Regarding this issue, we empathize that despite short-term (e.g., $5 \mathrm{~min}$ ), cardiac BRS was lowered by warm water bathing which did not elicit remarkable core temperature elevation. Elevation of core temperature and hypohydration are believed to impair orthostatic tolerance [5, 13, 21]. For example, $3 \%$ body mass deficit and $\sim 0.7{ }^{\circ} \mathrm{C}$ concomitant elevation of core temperature had been shown to exacerbate standing-related reductions in the middle cerebral artery blood flow velocity and impair orthostatic tolerance [5]. From the standpoint of safety, further study to determine the impact of prolonged warm water bathing is needed.

\section{Conclusion}

Before and immediately after the 5-min warm water immersion, we compared RRI responses to abrupt drop of SBP induced by the single sit-stand movement in men. The present data indicate that even a short-term warm water immersion deteriorates cardiac BRS and that individuals with stiffer arteries are relatively more susceptible to WWI because of their poor baseline BRS. This might be one of the causes of bathing-related falling in elderly persons as well as frailty. Further studies to determine the impact of prolonged bathing as well as sex difference are needed.

\section{Abbreviations}

BP: Blood pressure; BRS: Baroreflex sensitivity; HR: Heart rate; MAP: Mean arterial pressure; RRI: R-R interval; SV: Stroke volume; WWI: Warm water immersion.

\section{Acknowledgements}

We appreciate the commitment of all participants of this study. We also thank Ms. Mitsuho Hanamoto for her technical assistance.

\section{Authors' contributions}

JS decided conception and design of research. JS and TT performed experiments, analyzed data, interpreted results of experiments. JS prepared figures. JS drafted manuscript. All authors edited and revised manuscript. Both authors read and approved the final manuscript.

\section{Funding}

This study was funded by Japan Health \& Research Institute Research (to Jun Sugawara). The funding body had no role in the design of this study, data collection, interpretation of data or in writing of the manuscript.

\section{Availability of data and materials}

The datasets used and/or analyzed during the current study are available from corresponding author on reasonable request.

\section{Ethical approval and consent to participate}

All experimental procedures and protocols conformed to the Declaration of Helsinki and were approved by the institutional review board (\#2016-683, National Institute of Advanced Industrial Science and Technology). All subjects provided written informed consent before participation.

\section{Consent for publication}

Not applicable.

\section{Competing interests}

The authors declare that they have no competing interests.

\section{Author details}

${ }^{1}$ Human Informatics and Interaction Research Institute, National Institute of Advanced Industrial Science and Technology, 1-1-1 Higashi, Tsukuba, Ibaraki 305-8566, Japan. ${ }^{2}$ Institute for Exercise and Environmental Medicine, Texas Health Presbyterian Hospital Dallas, Dallas, TX, USA. ${ }^{3}$ Department of Neurology and Neurotherapeutics, University of Texas Southwestern Medical Center, Dallas, TX, USA.

Received: 10 February 2020 Accepted: 3 July 2020

Published online: 09 July 2020

\section{References}

1. Ali YS, Daamen N, Jacob G et al (2000) Orthostatic intolerance: a disorder of young women. Obstet Gynecol Surv 55:251-259

2. Armentano R, Megnien JL, Simon A et al (1995) Effects of hypertension on viscoelasticity of carotid and femoral arteries in humans. Hypertension 26:48-54

3. Beever $\mathrm{R}$ (2010) The effects of repeated thermal therapy on quality of life in patients with type II diabetes mellitus. J Altern Complement Med 16:677-681

4. Brunt VE, Howard MJ, Francisco MA et al (2016) Passive heat therapy improves endothelial function, arterial stiffness and blood pressure in sedentary humans. J Physiol 594:5329-5342

5. Carter R 3rd, Cheuvront SN, Vernieuw CR et al (2006) Hypohydration and prior heat stress exacerbates decreases in cerebral blood flow velocity during standing. J Appl Physiol (1985) 101:1744-1750

6. Convertino VA (1998) Gender differences in autonomic functions associated with blood pressure regulation. Am J Physiol 275:R1909-R1920

7. Crandall CG (2000) Carotid baroreflex responsiveness in heat-stressed humans. Am J Physiol Heart Circ Physiol 279:H1955-H1962

8. Crandall CG, Zhang R, Levine BD (2000) Effects of whole body heating on dynamic baroreflex regulation of heart rate in humans. Am J Physiol Heart Circ Physiol 279:H2486-H2492

9. Frey MA (1985) Hoffler GW (1988) Association of sex and age with responses to lower-body negative pressure. J Appl Physiol 65:1752-1756

10. Fritsch JM, Smith ML, Simmons DT et al (1991) Differential baroreflex modulation of human vagal and sympathetic activity. Am J Physiol 260:R635-R641

11. Keller DM, Cui J, Davis SL et al (2006) Heat stress enhances arterial baroreflex control of muscle sympathetic nerve activity via increased sensitivity of burst gating, not burst area, in humans. J Physiol-London 573:445-451

12. Laukkanen T, Khan H, Zaccardi F et al (2015) Association between sauna bathing and fatal cardiovascular and all-cause mortality events. Jama Intern Med 175:542-548

13. Lind AR, Leithead CS, Mcnicol GW (1968) Cardiovascular changes during syncope induced by tilting men in the heat. J Appl Physiol 25:268-276

14. Low DA, Wingo JE, Keller DM et al (2009) Dynamic cerebral autoregulation during passive heat stress in humans. Am J Physiol Regul Integr Comp Physiol 296:R1598-R1605

15. Mattace-Raso FU, Van Den Meiracker AH, Bos WJ et al (2007) Arterial stiffness, cardiovagal baroreflex sensitivity and postural blood pressure changes in older adults: the Rotterdam Study. J Hypertens 25:1421-1426

16. Mattace-Raso FU, Van Der Cammen TJ, Knetsch AM et al (2006) Arterial stiffness as the candidate underlying mechanism for postural blood pressure changes and orthostatic hypotension in older adults: the Rotterdam Study. J Hypertens 24:339-344

17. Miyata M, Tei C (2010) Waon therapy for cardiovascular disease: innovative therapy for the 21st century. Circ J 74:617-621

18. Monahan KD, Tanaka H, Dinenno FA et al (2001) Central arterial compliance is associated with age- and habitual exercise-related differences in cardiovagal baroreflex sensitivity. Circulation 104:1627-1632

19. Rowe JW (1987) Clinical consequences of age-related impairments in vascular compliance. Am J Cardiol 60:68G-71G

20. Rowell LB (1993) Human Cardiovascular Control. Oxford University Press, NewYork 
21. Schlader ZJ, Wilson TE, Crandall CG (2016) Mechanisms of orthostatic intolerance during heat stress. Auton Neurosci 196:37-46

22. Sugawara J, Tanabe T, Miyachi M et al (2003) Non-invasive assessment of cardiac output during exercise in healthy young humans: comparison between Modelflow method and Doppler echocardiography method. Acta Physiol Scand 179:361-366

23. Suzuki M, Shimbo T, Ikaga T et al (2019) Incidence and characteristics of bath-related accidents. Intern Med 58:53-62

24. Tomoto T, Sugawara J, Nogami Y et al (2015) The influence of central arterial compliance on cerebrovascular hemodynamics: insights from endurance training intervention. J Appl Physiol (1985) 119:445-451

25. Wesseling KH, Jansen JR, Settels JJ et al (1993) Computation of aortic flow from pressure in humans using a nonlinear, three-element model. J Appl Physiol 74:2566-2573

26. White DD, Gotshall RW, Tucker A (1996) Women have lower tolerance to lower body negative pressure than men. J Appl Physiol 80:1138-1143
27. Yamazaki F, Matsumura F, Nagata J et al (2001) Spontaneous arterial baroreflex control of the heart rate during head-down tilt in heat-stressed humans. Eur J Appl Physiol 85:208-213

28. Yamazaki F, Sone R (2000) Modulation of arterial baroreflex control of heart rate by skin cooling and heating in humans. J Appl Physiol (1985) 88:393-400

29. Yamazaki F, Sone R (2005) Whole-body heating slows carotid baroreflex response in human subjects. Eur J Appl Physiol 94:690-696

30. Zhang R, Zuckerman JH, Giller CA et al (1998) Transfer function analysis of dynamic cerebral autoregulation in humans. Am J Physiol 274:H233-H241

\section{Publisher's Note}

Springer Nature remains neutral with regard to jurisdictional claims in published maps and institutional affiliations.
Ready to submit your research? Choose BMC and benefit from:

- fast, convenient online submission

- thorough peer review by experienced researchers in your field

- rapid publication on acceptance

- support for research data, including large and complex data types

- gold Open Access which fosters wider collaboration and increased citations

- maximum visibility for your research: over 100M website views per year

At $\mathrm{BMC}$, research is always in progress.

Learn more biomedcentral.com/submissions 